\title{
Lipid Metabolism Disorder
}

National Cancer Institute

\section{Source}

National Cancer Institute. Lipid Metabolism Disorder. NCI Thesaurus. Code C97092.

An inherited metabolic disorder caused by an enzyme deficiency, resulting in an inability to oxidize fatty acids for energy production. 